\title{
Increased uptake of social security benefits among long-term survivors of cancer in childhood, adolescence and young adulthood: a Norwegian population-based cohort study
}

\author{
S Ghaderi ${ }^{\star, 1}$, A Engeland ${ }^{1,2}$, D Moster ${ }^{1,2,3}$, E Ruud $^{4}$, A Syse ${ }^{5}$, F Wesenberg ${ }^{4,6}$ and T Bjørge ${ }^{1,2}$ \\ ${ }^{1}$ Department of Global Public Health and Primary Care, University of Bergen, Bergen 5018, Norway; ${ }^{2}$ Norwegian Institute of Public \\ Health, Bergen 5018, Norway; ${ }^{3}$ Department of Paediatrics, Haukeland University Hospital, Bergen 5021, Norway; ${ }^{4}$ Department of \\ Paediatric Medicine, Women and Children's Division, Oslo University Hospital, Oslo 0424, Norway; ${ }^{5}$ Faculty of Medicine, \\ University of Oslo, Oslo 0316, Norway and ' Norwegian Social Research, Oslo 0208, Norway
}

Background: As the number of cancer survivors increases, their health and welfare have come into focus. Thus, long-term medical consequences of cancer at a young age ( $<25$ years), obtained from social security benefit records, were studied.

Methods: Standardised incidence ratios (SIRs) of long-term medical consequences for 5-year cancer survivors, born during 1965-1985, were explored by linking population-based registries in Norway.

Results: Among the 5-year cancer survivors (4031 individuals), 29.7\% received social security benefits. The survivors had an overall 4.4 times (95\% confidence interval $(95 \% \mathrm{Cl})$ : 4.1-4.6) higher risk of social security benefit uptake than the cancer-free population. Survivors of malignancies of bone and connective tissues (SIR: 10.8; 95\% Cl: 9.1-12.9), CNS tumours (SIR: 7.7; 95\% Cl: 6.9-8.6) and malignancies of the haematopoietic system (SIR: 6.1; 95\% Cl: 5.3-7.0) had the highest risks of social security benefits uptake. The most notified causes of social security benefit uptake were diseases of the nervous system, and injury and poisoning.

Conclusion: The uptake of social security benefits among 5-year cancer survivors increased substantially and it may represent a solid outcome measure for the burden of the most severe late effects, especially in countries with comparable social welfare systems.

Owing to the improvement in childhood cancer treatment over the past few decades, the mortality of cancer patients has been substantially reduced (Ghaderi et al, 2012) and the overall survival rate of children is now about $80 \%$ (SEER, 2011). The types of cancer affecting young individuals $(<25$ years) as well as their long-term consequences are distinctive and differ from those developing at older ages. As the number of cancer survivors increases, the long-term consequences of cancer and cancer therapy are becoming even more important, and as a result, more attention is directed at the follow-up into adulthood.

Long-term survivors ( $>5$ years survival after diagnosis) of cancers at a young age are at increased risk of late morbidity compared with the cancer-free population, due to treatmentrelated subsequent neoplasms, effects of specific childhood cancer types and treatments or simply the young age at diagnosis (Oeffinger et al, 2006; Geenen et al, 2007; Diller et al, 2009; Whelan 
et al, 2010; Armstrong et al, 2011; Woodward et al, 2011). A study on late effects showed that approximately $28 \%$ of the long-term survivors (excluding survivors of acute myeloid leukaemia (AML)) have a severe chronic medical condition compared with, approximately, $6 \%$ of the siblings and $17 \%$ of the AML survivors (Mulrooney et al, 2008). Another study showed that $27.5 \%$ of the cancer survivors have reported a severe or life-threatening health condition compared with 5.2\% among siblings (Oeffinger et al, 2006).

Cancer survivors increasingly need supportive measures provided by the society, indicating the long-term consequences of cancer on their health, working ability and financial situation. Studies from Norway and Sweden have reported a reduced working ability, an increased need for financial support and consequently a greater need for uptake of social security benefit of various kinds compared with the reference population (Hjern et al, 2007; Johannesen et al, 2007; Thorsen et al, 2011).

Previous studies on long-term consequences of cancer are mainly based on questionnaires, reviews of published articles or retrospective cohort studies (Robison et al, 2002; Shaw et al, 2004; Hawkins et al, 2008; Diller et al, 2009; Kuehni et al, 2012). To our knowledge, there are only a few population-based cohort studies on the uptake of social security benefits among cancer survivors (Hjern et al, 2007; Johannesen et al, 2007). The National Insurance Scheme (NIS) in Norway provides disability benefits for all individuals residing in Norway whose health conditions are of sufficient severity to create a serious economic problem (The Norwegian Labour and Welfare Administration, 2012). We hypothesised that the uptake of social security benefits may be used as a surrogate marker of chronic health impairments due to severe late effects after cancer. We expected an increasing trend in the uptake of social security benefits among long-term survivors of cancer in young ages. The aim of this study was, thus, to explore the long-term medical consequences of cancer in young ages as indicated by later social security benefit uptake by linking population-based national registries in Norway.

\section{MATERIALS AND METHODS}

\section{Data sources}

Cancer Registry of Norway. The Cancer Registry of Norway (CRN) has received information on all cancer cases in the Norwegian population since 1953. Informations from clinical and pathological notifications and death certificates are the main reporting sources. These sources provide information about site, histological type and stage of disease at the time of diagnosis (Cancer in Norway, 2011). Registration of topography was based on a modified version of International Classification of Diseases (ICD-7) until 1992 (WHO, 2011). Since 1993 and onwards, the coding has been based on ICD-O-2. Through 1992, tumour morphology was coded according to the Manual of Tumour Nomenclature and Coding, and since 1993, ICD-O morphology codes have been adopted. Non-solid tumours have been coded according to a separate coding system from 1986 (Larsen et al, 2009). Unfortunately, information on primary or subsequent treatment is not available.

National Insurance Scheme. All residents of Norway are insured by the National Insurance Scheme (NIS) regardless of their nationality or job status. The only crucial condition for membership in the NIS is that the enrolee must have been a legal resident of Norway for at least 12 months (NIS, 2010). NIS provides disability benefits for people with medical health conditions deemed sufficiently severe to cause an economic burden, and it further includes attendance benefits, basic benefits, disability pensions and medical rehabilitation benefits (Table 1). Registration of social security benefit records by NIS started in 1992 and included both new and existing benefits.

Persons may receive more than one benefit, and the duration of use varies according to need as decided by the medical personnel in collaboration with representatives from the NIS. The diagnoses associated with the benefits are recorded along with the dates at which the benefits were granted (NIS, 2010). These diagnoses are based on medical examinations and are classified according to the ICD-9 (used by NIS from 1992 to 1998) and ICD-10 (used by NIS after 1998). For simplicity, diagnoses are only presented in the ICD-10 version in this paper. Data from NIS were registered from 1992 and were available to us for the period of 1992-2006 (2002-2007 for medical rehabilitation benefits).

Norwegian Central Population Registry. The Norwegian Central Population Registry (NCPR) contains demographic information on all residents in Norway since 1960, including date of birth, place of residence and date of emigration or death (Hammer, 2002).

Study cohort. All children born alive in Norway during 1965-1985, approximately 1.2 million individuals (including 5802 individuals with cancer diagnosed before the age of 25years), were defined as our study cohort (625349 males and 590709 females). The individuals were followed up into adulthood, until they reached between 24 and 44 years of age at the end of the follow-up. Among the cancer patients, 1499 died within 5 years after diagnosis (1409 cancer-related deaths), while 294 deaths occurred after 5 years (234 cancer-related deaths). In the study cohort, all 5-year cancer survivors were identified and were further grouped as children (0-14 years), adolescents (15-19 years) and young adults (20-24 years) based on age at diagnosis - a total of 4031 individuals (Figure 1).

The cohort was followed from birth until death, emigration or as on 31 December 2009 by linking NCPR, CRN and NIS, using the unique 11-digit personal identification number assigned to all individuals living in Norway after 1960.

\begin{tabular}{|c|c|}
\hline Kind of benefit & Descriptions (Johannesen et al, 2007; Ministry of Labour, 2011) \\
\hline Attendance benefit & $\begin{array}{l}\text { If a disabled person is in need of special attention or there is a need for special supervision; for example, extra nursing or need for } \\
\text { special care, training, help with getting up/going to bed, eating and personal hygiene. It can be given to all ages. }\end{array}$ \\
\hline Basic benefit & $\begin{array}{l}\text { If a disability involves extra expenses (in cases involving prostheses, support bandages, extra costs of running/operation of technical } \\
\text { aids, transport, guide dog, etc.). It can be given to all ages. }\end{array}$ \\
\hline Disability pension & $\begin{array}{l}\text { After a period with medical rehabilitation benefits, a disability pension may be given if working capacity is permanently reduced by at } \\
\text { least } 50 \% \text { owing to illness or injury, provided a person is at least } 18 \text { years of age. }\end{array}$ \\
\hline $\begin{array}{l}\text { Medical rehabilitation } \\
\text { benefit }\end{array}$ & $\begin{array}{l}\text { It is given for up to } 1 \text { year ( } 66 \% \text { of yearly income) if a person is at least } 18 \text { years of age and the ability to work has been impaired by at } \\
\text { least } 50 \% \text { owing to an illness or injury. }\end{array}$ \\
\hline
\end{tabular}




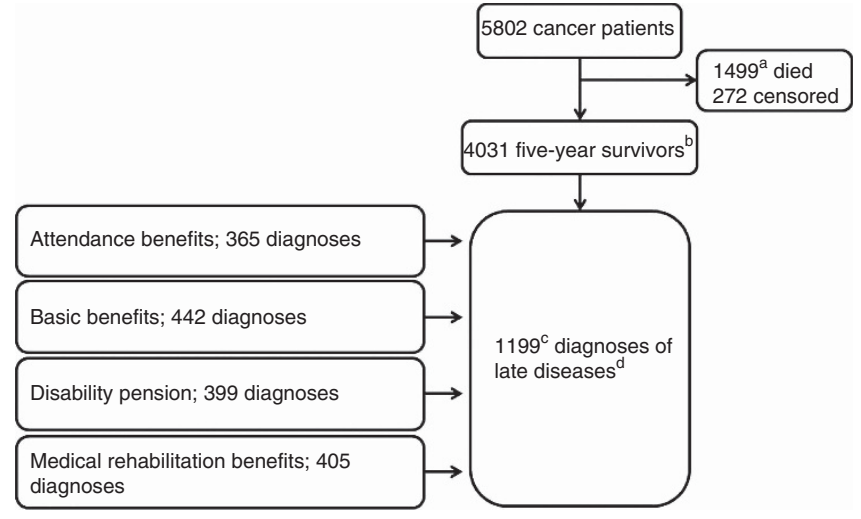

Figure 1. Establishment and follow-up of the cancer cohort. 'In all, 1409 were cancer-related deaths; ${ }^{b} 294$ deaths occurred among the 5 -year cancer survivors (234 cancer-related deaths); 'only the first registered late effect was considered; and defined as the prevalence of any medical condition of certain severity that could qualify for uptake of social security benefits among the 5 -year survivors.

Statistical analysis. Diseases extracted from attendance benefits, basic benefits, disability pensions and medical rehabilitation benefits (considered separately and in combination) were described by the standardised incidence ratio (SIR).

Standardised incidence ratio was used as an indication for risk of developing a specific disease among the cancer survivors relative to the occurrence of the same disease in the cancer-free population (the general population). In this study, the entire cancer-free population was used as the comparison group. For the cancer survivors, diseases extracted from the four social security benefits will be referred to as 'late effects' in this paper, as they have been assumed to be the cause for uptake of social security benefits. Furthermore, we defined the late effects as prevalence of any medical condition of a certain severity that could qualify for uptake of social security benefits among the 5-year survivors.

The SIR was calculated as the ratio of the observed to the expected numbers of benefit-related health problems. The expected numbers were the number of person-years in a specific disease category (late effects) multiplied by the prevalence of the same disease in the cancer-free population of the same age and sex during the period of observation. For each SIR, a 95\% confidence interval (95\% CI) was calculated, assuming a Poisson distribution of the observed number of cases.

The number of late effects was observed and the person-years among the cancer survivors were calculated in 5-year age-groups (5-9 ... 40-44 years) and 5/10-year calendar periods (1970-1974, 1975-1984, 1985-1994, 1995-2004 and 2005-2009) for each sex. For the cancer survivors, the time at risk for a late effect began at 5 years after the primary diagnosis and ended at death, emigration or as on 31 December 2009. For all late-effect diagnoses, rates were only calculated for the years 1992-2006 (2002-2007 for medical rehabilitation benefits).

Late effects were divided into the following diagnostic groups (ICD-10):

- Infectious and parasitic diseases (A00-B99).

- Neoplasms (C00-D48).

- Endocrine, nutritional and metabolic diseases, and immunity disorders (E00-E90).

- Diseases of the blood and blood-forming organs (D50-D89).

- Mental disorders (F00-F99).

- Diseases of the nervous system (G00-G99).

- Diseases of the sense organs (H00-H95).

- Diseases of the circulatory system (I00-I99).
- Diseases of the respiratory system ((J00-J99).

- Diseases of the digestive system (K00-K93).

- Diseases of the genitourinary system (N00-N99).

- Complications of pregnancy, childbirth and the puerperium (O00-O99).

- Diseases of the skin and subcutaneous tissue (L00-L99).

- Diseases of the musculoskeletal system and connective tissue (M00-M99).

- Certain conditions originating in the perinatal period (P00-P96).

- Symptoms, signs and ill-defined conditions (R00-R99).

- Injury and poisoning (S00-T99, V-Z).

Diseases amounting to fewer than 10 cases in all of the social security benefit groups (attendance benefit, basic benefit, disability pension and medical rehabilitation benefit) were grouped and presented as 'others'. All individuals with benefits associated with conditions present at birth/early life were excluded from the study population; these included congenital anomalies (ICD-10: Q00-Q99) and cerebral palsy (ICD-10: G80).

When the characteristics of the 5-year cancer survivors were described with regard to diagnoses extracted from social security benefits in general, only the first registered diagnosis was considered (Table 2). Among the cancer survivors, 366 survivors received two kinds, 132 survivors received three kinds and 5 survivors received four kinds of social security benefits (data not shown). When late effects within each social security benefit category were described, the first registered late effect of each diagnosis was considered (Table 3).

Ethics. The study was approved by the Regional Committee for Medical Research Ethics of Western Norway.

\section{RESULTS}

A total of 5802 individuals were diagnosed with cancer before the age of 25 years, of which 4031 individuals (2232 males and 1799 females) became 5 -year cancer survivors. Survivors were followed for an average of 13.2 years beginning 5 years after diagnosis (range $0-39.3$ years). The corresponding average follow-up time for the cancer-free population was 34.2 years (range $0-45$ years).

Cancer survivors. Diagnoses were extracted from the NIS in Norway (Figure 1). Considering all social security benefits combined, cancer survivors had a higher risk of social security benefit uptake than the cancer-free population (SIR: 4.4; 95\% CI: 4.1-4.6); higher risks were observed for male survivors (SIR: 4.7; 95\% CI: 4.4-5.1). The risk increased both by year of birth and primary cancer diagnosis. Younger age at primary cancer diagnosis increased the risk of uptake of social security benefits. Survivors of malignancies of bone and connective tissues (SIR: 10.8; 95\% CI: 9.1-12.9), CNS tumours (SIR: 7.7; 95\% CI: 7.9-8.6) and malignancies of the haematopoietic system (SIR: 6.1; 95\% CI: 5.3-7.0) had the highest risks for social security benefit uptake (Table 2).

Social security benefits. A total of $29.7 \%$ of the survivors were recipients of social security benefits compared with $10.8 \%$ of the cancer-free population. Among survivors, 9.1\% received attendance benefits, which are financial compensations for the use of services (e.g. nursing or home health care). Attendance benefit is perhaps an indication of both the severity of the burden of illness and disability, as well as the economic impact on the survivors. The corresponding percentage among the cancer-free population was $1.1 \%$. The uptake of basic benefits granted if a person incurs substantial expenses as a result of health problems was $11.0 \%$ among the survivors compared with $2.2 \%$ in the cancer-free population. Overall, $8.4 \%$ of the survivors were disability pension recipients, indicating a permanent reduction in working capacity 


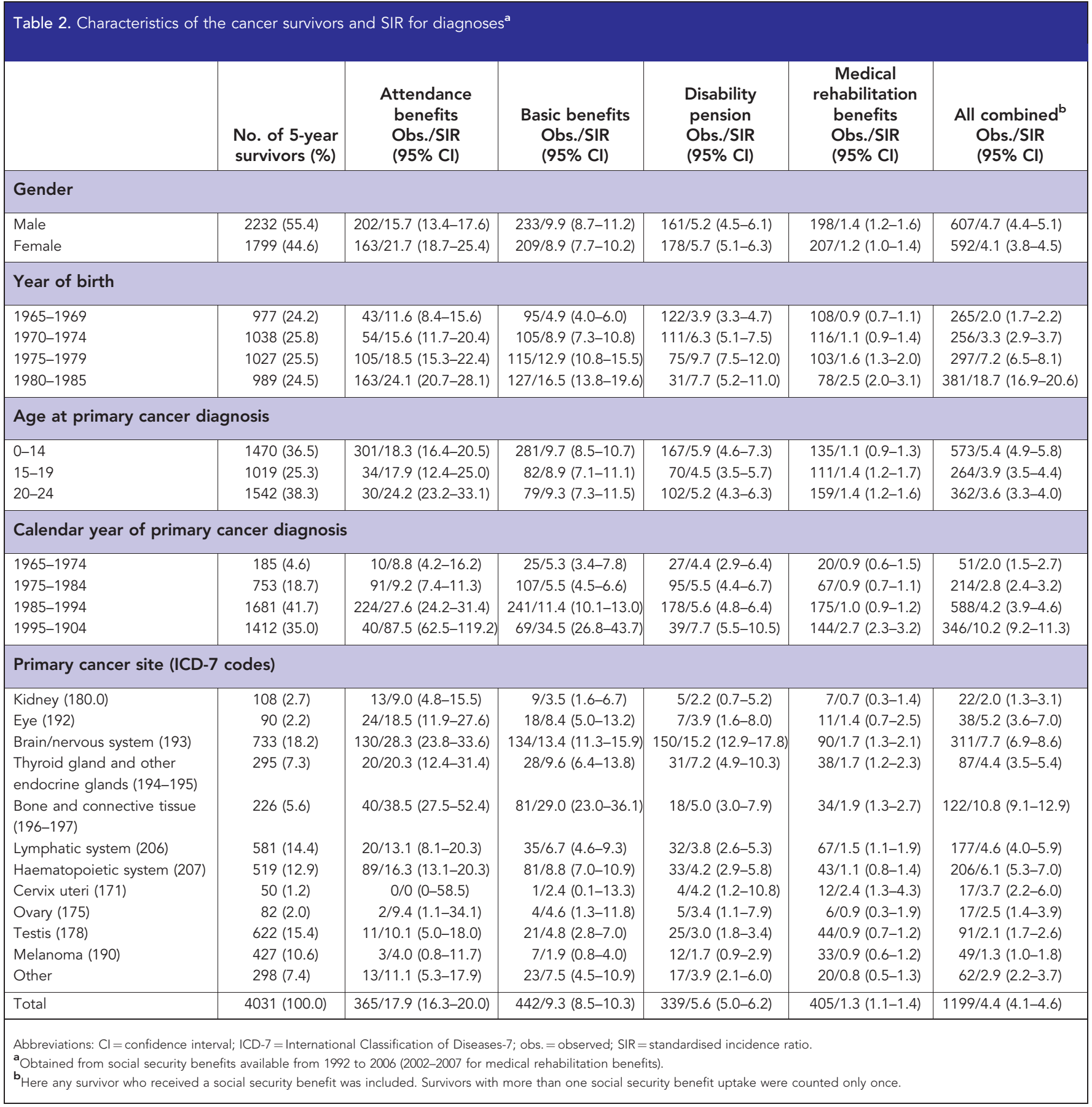

by at least $50 \%$ compared with $2.2 \%$ in the cancer-free population. The uptake of medical rehabilitation benefits was $10.1 \%$ among the survivors compared with $7.5 \%$ in the cancer-free population (data not shown).

Attendance benefits. A total of 365 diagnoses (among the cancer survivors) were extracted from attendance benefits (55.3\% males), where the overall SIR was 17.9 times higher than expected (95\% CI: 16.3-20.0). The risk increased by year of birth and primary cancer diagnosis. Survivors diagnosed during young adult age (20-24 years) had the highest risk of late effects. Survivors of malignancies of bone and connective tissues (SIR: 38.5 ; 95\% CI: 27.5-52.4) and CNS tumours (SIR: 28.3; 95\% CI: 23.8-33.6) had the highest risks for late effects and consequently the uptake of attendance benefits (Table 2).
Survivors had 26.0 (95\% CI: 17.3-37.6) and 7.4 (95\% CI: 3.5-13.6) times higher risks of attendance benefits uptake due to injury and poisoning, and diseases of the sense organs, respectively, compared with the cancer-free population (Table 3).

Basic benefits. A total of 442 diagnoses (among the cancer survivors) were obtained from basic benefits (54.5\% males), where the overall SIR was 9.3 times higher than expected (95\% CI: 8.5-10.3), and with higher risk among male survivors (SIR: 9.9; 95\% CI: 8.7-11.2). The risk of late effects increased by year of birth and primary cancer diagnosis. Survivors of malignancies of bone and connective tissues (SIR: 29.0; 95\% CI. 23.0-36.1) and CNS tumours (SIR: 13.4; 95\% CI: 11.3-15.9) had the highest risks of late effects and consequently basic benefit uptake (Table 2). 
Table 3. SIRs of receiving social security benefits available from 1992 to 2006 (2002-2007 for medical rehabilitation benefits) among 5-year cancer survivors

\begin{tabular}{c|c|c|c}
$\begin{array}{c}\text { Attendance benefits } \\
\text { Obs./SIR }(95 \% \mathrm{Cl})\end{array}$ & $\begin{array}{c}\text { Basic benefits } \\
\text { Obs./SIR }(95 \% \mathrm{Cl})\end{array}$ & $\begin{array}{c}\text { Disability pension } \\
\text { Obs./SIR }(95 \% \mathrm{Cl})\end{array}$ & $\begin{array}{c}\text { Medical rehabilitation benefits } \\
\text { Obs./SIR }(95 \% \mathrm{Cl})\end{array}$ \\
\hline
\end{tabular}

\section{Neoplasm

\begin{tabular}{|l|l}
\hline Men & $160 / 3130.5(2681.2-3655.2)$ \\
Women & $120 / 3573.0(2987.7-4273.1)$ \\
Total & 280/3328.3 (2960.7-3742.3)
\end{tabular}

\begin{tabular}{|l|}
$152 / 2429.6(2072.7-2848.5)$ \\
$123 / 1954.4(1637.8-2332.2)$ \\
$275 / 2176.4(1933.8-2449.5)$
\end{tabular}

93/1306.4 (1054.4-1600.5)

99/1640.3 (1333.4-1997.0)

$192 / 1460.0(1267.4-1681.8)$
11/10.2 (5.1-18.2)

$10 / 5.7(2.7-10.5)$

$21 / 7.3(4.5-11.1)$

\section{Infectious and parasitic disease}

\begin{tabular}{|l|c|c|c|r|}
\hline Men & - & $1 / 22.8(0.6-127.3)$ & - & $17 / 2.6(1.5-4.2)$ \\
Women & - & $0 / 0(0-64.4)$ & - & $27 / 3.2(2.3-4.8)$ \\
Total & - & $1 / 10.4(0.3-58.0)$ & - & $44 / 3.1(2.2-4.1)$ \\
\hline
\end{tabular}

Endocrine, nutritional and metabolic disease and immunity disorder

\begin{tabular}{|l|r|r|r|r|}
\hline Men & $6 / 4.5(1.6-9.8)$ & $8 / 2.3(1.0-4.6)$ & $5 / 8.5(2.8-19.8)$ & - \\
Women & $2 / 2.1(0.3-7.7)$ & $5 / 1.9(0.6-4.4)$ & $9 / 12.6(5.7-23.9)$ & $1 / 4.0(0.1-22.4)$ \\
Total & $8 / 3.5(1.5-7.0)$ & $13 / 2.1(1.0-3.5)$ & $14 / 10.6(5.8-17.8)$ & $1 / 2.3(0-8.5)$
\end{tabular}

\section{Mental disorders}

\begin{tabular}{|l|r|r|r|r}
\hline Men & $10 / 1.7(0.8-3.2)$ & $7 / 1.5(0.6-3.1)$ & $36 / 1.6(1.1-2.2)$ & $12 / 0.7(0.4-1.2)$ \\
Women & $6 / 2.0(0.8-4.5)$ & $11 / 3.2(1.6-5.7)$ & $30 / 1.8(1.2-2.6)$ & $8 / 0.5(0.2-1.0)$ \\
Total & $16 / 1.9(1.1-3.1)$ & $18 / 2.2(1.3-3.5)$ & $66 / 1.7(1.3-2.2)$ & $20 / 0.6(0.4-0.9)$
\end{tabular}

Disease of the nervous system

\begin{tabular}{|l|r|}
\hline Men & $9 / 3.2(1.5-6.2)$ \\
Women & $8 / 5.7(2.4-11.2)$ \\
Total & $17 / 4.2(2.4-6.7)$
\end{tabular}

$12 / 4.5(2.3-7.9)$
$10 / 4.8(2.3-8.8)$
$22 / 4.7(2.9-7.1)$

14/5.5 (3.0-9.2)

$14 / 4.4(2.4-7.3)$

$28 / 4.8(3.2-7.0)$

2/3.6 (0.4-13.1)

$1 / 1.3(0-7.3)$

$3 / 2.3(0.5-6.6)$

Disease of the sense organs

\begin{tabular}{|l|r|}
\hline Men & $3 / 3.9(0.8-11.4)$ \\
Women & $7 / 11.9(4.8-24.5)$ \\
Total & $10 / 7.4(3.5-13.6)$
\end{tabular}

$7 / 5.7(2.3-11.8)$

$15 / 13.6(7.6-22.4)$

$22 / 9.5(5.9-14.3)$

$2 / 5.1(0.6-18.4)$
$1 / 2.1(0.1-11.8)$
$3 / 3.4(0.7-10.0)$

$1 / 1.4(0-5.0)$

$2 / 1.7(0.2-6.2)$

$3 / 1.6(0.1-4.5)$

\section{Disease of the digestive system}

\begin{tabular}{l|c|r|}
\hline Men & - & $5 / 2.0(0.7-4.7)$ \\
Women & - & $8 / 2.1(1.0-4.0)$ \\
Total & - & $14 / 2.0(1.1-3.4)$
\end{tabular}

3/5.0 (1.0-14.5)

$3 / 3.4(0.7-9.9)$
9/3.8 (1.7-7.1)

$3 / 1.2(0.2-3.5)$

$12 / 2.4(1.3-4.3)$

\section{Disease of the genitourinary system}

\begin{tabular}{|l|c|c|}
\hline Men & - & $1 / 18.6(0.5-103.6)$ \\
Women & - & $1 / 9.8(0.2-54.7)$ \\
Total & - & $2 / 12.6(0.2-35.1)$
\end{tabular}

Disease of the musculoskeletal system and connective tissue

\begin{tabular}{|l|l|r|}
\hline Men & $3 / 8.5(1.7-24.9)$ & $4 / 3.3(0.9-8.6)$ \\
Women & $3 / 4.9(1.0-14.2)$ & $9 / 4.1(1.9-7.8)$ \\
Total & $6 / 6.1(2.2-13.2)$ & $13 / 3.8(2.0-6.4)$
\end{tabular}

Disease of the skin and subcutaneous tissue

\begin{tabular}{|l|l|r|}
\hline Men & - & $6 / 1.7(0.6-3.7)$ \\
Women & $2 / 5.3(0.6-19.0)$ & $7 / 1.5(0.6-3.1)$ \\
Total & $2 / 2.3(0-6.3)$ & $13 / 1.6(0.8-2.7)$
\end{tabular}

Certain conditions origination in the perinatal period

\begin{tabular}{|c|c|c|c|c|}
\hline $\begin{array}{l}\text { Men } \\
\text { Women } \\
\text { Total }\end{array}$ & $\begin{array}{l}- \\
-\end{array}$ & $\begin{array}{l}- \\
- \\
-\end{array}$ & $\begin{array}{l}- \\
- \\
-\end{array}$ & $\begin{array}{r}56 / 0.9(0.7-1.2) \\
59 / 0.8(0.6-1.1) \\
115 / 0.9(0.7-1.0)\end{array}$ \\
\hline \multicolumn{5}{|c|}{ Injury and poisoning } \\
\hline $\begin{array}{l}\text { Men } \\
\text { Women } \\
\text { Total }\end{array}$ & $\begin{array}{l}14 / 18.1(9.9-30.4) \\
14 / 42.9(23.5-72.0) \\
28 / 26.0(17.3-37.6)\end{array}$ & $\begin{array}{l}24 / 12.1(7.8-18.1) \\
20 / 21.3(13.0-32.9) \\
44 / 15.3(11.1-20.6)\end{array}$ & $\begin{array}{r}6 / 2.0(0.8-4.5) \\
4 / 2.1(0.6-5.3) \\
10 / 2.1(1.0-3.8)\end{array}$ & $\begin{array}{l}17 / 2.7(1.6-4.3) \\
18 / 1.4(0.8-2.2) \\
35 / 1.8(1.3-2.5)\end{array}$ \\
\hline
\end{tabular}

$40 / 5.5(4.0-7.5)$

$37 / 3.7(2.6-5.0)$

$77 / 4.4(3.5-5.5)$
$2 / 1.3(0.2-4.6)$

$1 / 0.6(0-3.2)$

$3 / 0.9(0.1-2.2)$
$4 / 1.9(0.5-4.8)$
$13 / 2.5(1.3-4.2)$
$17 / 2.2(1.3-3.6)$
$51 / 1.0(0.8-1.3)$

$54 / 0.8(0.6-1.1)$

$105 / 0.9(0.8-1.1)$ 
Table 3. (Continued)

\begin{tabular}{|c|c|c|c|c|}
\hline & $\begin{array}{l}\text { Attendance benefits } \\
\text { Obs./SIR ( } 95 \% \mathrm{CI})\end{array}$ & $\begin{array}{c}\text { Basic benefits } \\
\text { Obs./SIR }(95 \% \mathrm{CI})\end{array}$ & $\begin{array}{l}\text { Disability pension } \\
\text { Obs./SIR }(95 \% \mathrm{CI})\end{array}$ & $\begin{array}{l}\text { Medical rehabilitation benefits } \\
\text { Obs./SIR }(95 \% \mathrm{Cl})\end{array}$ \\
\hline \multicolumn{5}{|l|}{ Others } \\
\hline $\begin{array}{l}\text { Men } \\
\text { Women } \\
\text { Total }\end{array}$ & $\begin{array}{l}2 / 0.9(0.1-3.1) \\
3 / 2.8(0.6-8.3) \\
5 / 1.5(0.5-3.5)^{a}\end{array}$ & $\begin{aligned} 11 / 4.7 & (2.3-8.4) \\
9 / 4.7 & (2.1-8.9) \\
20 / 4.7 & (2.8-7.3)^{b}\end{aligned}$ & $\begin{array}{l}1 / 1.0(0-3.6) \\
6 / 5.0(1.8-10.9) \\
7 / 3.1(1.3-6.4)^{c}\end{array}$ & $\begin{array}{c}1 / 0.2(0-1.3) \\
10 / 2.1(1.0-3.8) \\
11 / 1.2(0.6-2.2)^{d}\end{array}$ \\
\hline
\end{tabular}

Abbreviations: $\mathrm{Cl}=$ confidence interval; ICD-7 = International Classification of Diseases-7; obs. = observed; SIR = standardised incidence ratio

${ }^{\text {a }}$ This includes diseases of the circulatory system $(n=2)$, diseases of the respiratory system $(n=2)$, and symptoms, signs and ill-defined conditions ( $n=1$ ).

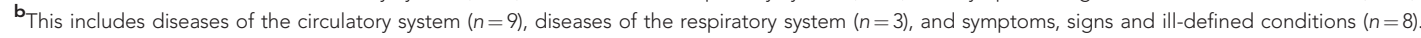

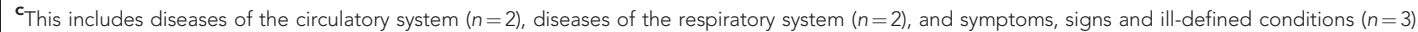

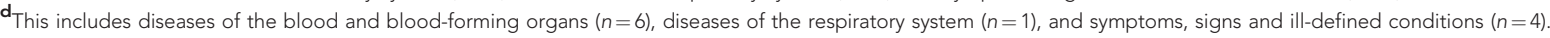

Following neoplasms, injury and poisoning (SIR: 15.3; $95 \%$ CI: 11.1-20.6) and diseases of the sense organs (SIR: 9.5; 95\% CI: 5.9-14.3), with higher risk among females survivors, were the main causes for basic benefit uptake among the cancer survivors (Table 3).

Disability pension. A total of 339 diagnoses (among the cancer survivors) were extracted from disability pension ( $47.7 \%$ males), where the overall SIR was approximately 5.6 times higher than expected (95\% CI: 5.0-6.2). Female survivors showed higher risks of disability pension uptake than male survivors (Table 2). Survivors who were diagnosed in young ages (0-14 years), survivors of CNS tumours (SIR: 15.2; 95\% CI: 12.9-17.8) as well as survivors with malignancies of the thyroid and other endocrine glands (SIR: 7.2; 95\% CI: 4.9-10.3) had very high risks of late effects, which could cause permanent reduction in working capacity by at least $50 \%$.

Following neoplasms, the most frequent causes of disability pension uptake (Table 3) were endocrine, nutritional and metabolic, and immunity disorders (SIR: 10.6; 95\% CI: $5.8-17.8$ ) and diseases of the nervous system (SIR: 4.8 ; 95\% CI: 3.2-7.0).

Medical rehabilitation benefits. A total of 405 diagnoses (among the cancer survivors) were retrieved from medical rehabilitation benefits (48.5\% males), where the overall SIR was 1.3 times higher than expected (95\% CI: 1.1-1.4). A slightly higher rate among the male survivors was observed (SIR: 1.4; 95\% CI: 1.2-1.6). The risk of late effects increased by year of birth. It was highest for those diagnosed during 1995-2004. Survivors of cervical cancer (SIR: 2.4; 95\% CI: 1.3-4.3) and malignancies of bone and connective tissue (SIR: 1.9 ; 95\% CI: 1.3-2.7) had the highest risks of medical rehabilitation benefit uptake (Table 2).

Following neoplasms, the most frequent causes for receiving medical rehabilitation benefits (Table 3) were diseases of the genitourinary system (SIR: 4.4; 95\% CI: 3.5-5.5) and infectious and parasitic diseases (SIR: 3.1; 95\% CI: 2.2-4.1).

\section{DISCUSSION}

This population-based study showed that 5-year cancer survivors (diagnosed younger than 25 years of age) in Norway are at increased risk of developing severe late effects, morbidities, chronic illnesses or disabilities that qualify for social security eligibility and uptake compared with the cancer-free population.

In Norway, all cancer treatment and follow-up is provided free of charge under the public health-care system. Thus, the medical costs are not directly related to active treatment but rather to consequences of cancer or late effects that are analysed here.
Hence, high medical costs may be the basis for social security benefit uptakes.

As mentioned earlier, diseases that qualify for uptake of social security benefits must be of a certain severity or economic burden. However, survivors can be affected by symptoms such as fatigue or pain without, thereby, qualifying for the uptake of social security benefit (Thorsen et al, 2011). The uptake of disability pension and medical rehabilitation benefits can mark not only a reduced working capacity, but also the financial impact of the disease on the person's financial situation. Attendance benefits and basic benefits are financial compensation that reflects the economic costs among the recipients of the social security benefits. We were not able to give an overview of all late effects or describe the quality of life among the cancer survivors. However, since Norway has a public health system and NIS is available to all the residents in the country, it was possible to describe changes in working abilities and an overall need for financial support and consequently the uptake of social security benefits among survivors as an indication of severe late effects.

Strengths and weaknesses. Among the strengths of this study are the cohort design and the use of population-based registries covering the entire population of Norway. We thus obtained reliable data with minimal loss to follow-up (0.2\%). Reporting of cancer cases to the Cancer Registry of Norway (CRN) has been compulsory since the early 1950s, with a high degree of completeness and quality (Larsen et al, 2009). Access to diagnoses through NIS, which are the notified causes for social security benefit uptake, offers the unique opportunity of being able to study long-term consequences of cancer among survivors relative to the cancer-free population. Therefore, uptake of social security benefits may represent a reliable source for describing the impact of severe or debilitating late effects among cancer survivors in Norway. This is a population-based study where the whole cancer-free population was used as the comparison group and therefore selection bias is unlikely. Diagnoses at NIS are recorded independently from the $\mathrm{CRN}$; thus, recall bias or reporting bias is implausible. When accounting for the underlying rate of disability and chronic illnesses in the cancer-free population, we are less likely to overestimate the burden associated with cancer. All individuals in Norway receive a unique 11-digit personal identification number at birth (or at immigration). This identification number makes it possible to follow-up the population, and to identify the cancer survivors' subsequent health problems that qualify for social security benefit uptake.

The main weakness of this study was the lack of information on cancer treatment (chemotherapy, radiation therapy and/or surgical procedures) at the individual level. The treatment protocols have changed significantly during our study period (Gustafsson et al, 2000; Stensheim et al, 2011); however, we do not have access 
to the treatment regimens undergone by each cancer patient. The data from NIS were registered from 1992 and were available to us only for the period up to 2006 (2002-2007 for medical rehabilitation benefits), and hence, we were unable to identify all benefits and the underlying diagnoses that occurred and were terminated before 1992. It is thus likely that the estimates presented here are somewhat lower than what they might have been if earlier benefits' information had been available. It is further likely that cancer survivors have other or additional problems that do not qualify for benefit uptake (Thorsen et al, 2011). Consequently, only 'disabling' or high-cost late effects reflected in the social security benefit uptake were measured in this study. More subjective late effects without such severe symptoms are thus likely underestimated.

Comparisons with the literature. In line with previous research, we found an increased risk of social security uptake due to various late effects among the cancer survivors compared with the observed risks in the cancer-free population (Haddy et al, 2001; Geenen et al, 2007; Hjern et al, 2007; Turner et al, 2009).

A Swedish study showed that survivors of CNS tumours had the highest risk of receiving economic social support (Hjern et al, 2007). In our study, this group of survivors had the second highest risk of any social security benefit uptake combined. However, survivors of CNS tumours had the highest risk of disability pension uptake compared with the cancer-free population, which indicates the significant consequences of this type of cancer among the survivors. The Norwegian study by Johannesen et al (2007), of cancer survivors diagnosed before 15 years of age and during the years 1970-1997, showed that uptake of any social security benefit was more frequent among survivors of CNS tumours compared with survivors of the malignancies of the Haematopoietic system, and this was in line with our findings. Another Norwegian study by Thorsen et al (2011), which was based on collected data from questionnaires, indicated an increased need for rehabilitation services due to cancer. They reported that $40 \%$ of the cancer survivors were not offered rehabilitation services suitable to their needs. When proper rehabilitation services are not provided, the risk of permanent disabilities may increase and hence increase the risk for uptake of any social security benefits.

A study by Mulrooney et al (2008), based on the Childhood Cancer Survivor Study (CCSS), included 5-year survivors diagnosed under the age of 21 years and during the years 1970-1986. They reported late outcomes among survivors graded with the National Cancer Institute Common Terminology Criteria for Adverse Events, where grades 3 and 4 are categorised as severe and life-threatening conditions, and compared the prevalence of each chronic condition among AML survivors with either siblings or non-AML CCSS survivors. In their study, $27.9 \%$ of the non-AML survivors had a serious health problem (grades 3 or 4) compared with $5.8 \%$ of the siblings and $16.5 \%$ of the AML survivors. Similarly, a study by Oeffinger et al (2006), also based on the CCSS, reported $27.5 \%$ severe or life-threatening conditions (grades 3 or 4 ) among the cancer survivors. Similar to the results reported by Mulrooney et al (2008), 30.5\% of the survivors in our study with similar age and year of primary cancer diagnosis, excluding the AML survivors, were recipients of social security benefits. In comparison to the results reported by Oeffinger et al (2006), 31.2\% of the survivors in our study were recipients of social security benefits.

Patterson et al (2012) studied endocrine health problems among young adult survivors of non-central nervous system childhood cancer during 2001-2005. Their study, which was based on a review of medical records, showed that the most common late effects after paediatric cancer therapy were endocrine and neuropsychological, whereas in our study, after neoplasms, the diagnostic groups associated with the various uptake rates varied by the type of social security benefits granted. Among those receiving attendance and basic benefits, injuries and poisoning and diseases of the sense organs were most common. Similarly, among those receiving disability pensions, endocrine diseases and diseases of the nervous system were most common, while diseases of the genitourinary system and infectious and parasitic diseases were most common among those receiving medical rehabilitation benefits.

A Dutch study reported an increased risk of cardiac dysfunction in childhood cancer survivors (Sieswerda et al, 2012). However, in our study, diseases of the circulatory system were not among the most notified causes for receiving social security benefits. A study on ocular late effects in childhood and adolescent cancer survivors has shown an increased risk of cataracts, glaucoma, legal blindness, double vision and dry eyes when compared with siblings (Whelan et al, 2010). This is in line with our findings, where diseases of the sense organs were frequently reported, excluding diagnoses from medical rehabilitation benefits.

The wide range of SIRs reported from different studies may be caused by the differences in types of studies (population-based, clinical-based or questionnaire), ages at diagnosis (the upperlimit), follow-up time, completeness and criteria for inclusion of childhood cancer form and/or treatment regimens. Many studies on late effects and diseases focus on treatment as one of the main factors. Inability to adjust for this factor in our analysis may explain some of the differences between our results and results from other studies (Bowers et al, 2005; Cardous-Ubbink et al, 2007; Bolling et al, 2008; Doi et al, 2009; Turner et al, 2009).

The uptake of social security benefit, which is studied here as a surrogate marker of late effects, is likely to be welfare-state-specific to some extent. In addition, country-specific labour market situations may influence the degree to which inclusion in working life is enabled.

Several studies focus on long-term consequences after a specific form of cancer or only one or very few late effects (Atkinson et al, 1998; Anderson, 2003; Bowers et al, 2005; Armstrong et al, 2009; Boman et al, 2009; Breslow et al, 2010; Ness et al, 2010). As we have access to the uptake rates of several different social security benefits reflecting various aspects of individuals' health and wellbeing, we were able to give an overview of many possible severe long-term consequences after cancer even though the total number of late effects was rather small.

The risk of disability pension uptake among cancer survivors was high, indicating a significant reduction in survivors' working capacity compared with the cancer-free population and perhaps pointing to areas where policy interventions may be relevant. Results of this study, which is based on the uptake of social security benefits, are similar to those reported from Oeffinger et al (2006) and Mulrooney et al (2008). The uptake of social security benefits might thus be a good indication of severe health problems. Increased risk of receiving social security benefits due to neoplasms shows the high impact of cancer diseases on survivors' general health and long-term working ability. It also shows the importance of lifelong screening for late effects among cancer survivors. This may reduce the incidence of chronic diseases and may also decrease treatment-related costs and health-care utilisation in general, as well as contribute to health awareness in this group (Klosky et al, 2012).

\section{CONCLUSION}

This study showed an increased risk of social security benefit uptake due to severe late effects among 5-year cancer survivors (diagnosed at young ages) relative to the cancer-free population. 
The results from this study, as well as other studies on this topic, show that continued follow-up over a prolonged period of time is necessary for early detection and intervention to reduce adverse health effects associated with health problems related to cancer and its treatment. Complementary care needs with cost containment is of outmost importance as the burden of long-term consequences of cancer in terms of incidence and prevalence continues to grow.

\section{ACKNOWLEDGEMENTS}

This study was supported by the Norwegian Cancer Society.

\section{REFERENCES}

Anderson NE (2003) Late complications in childhood central nervous system tumour survivors. Curr Opin Neurol 16(6): 677-683.

Armstrong GT, Liu Q, Yasui Y, Huang S, Ness KK, Leisenring W, Hudson MM, Donaldson SS, King AA, Stovall M, Krull KR, Robison LL, Packer RJ (2009) Long-term outcomes among adult survivors of childhood central nervous system malignancies in the Childhood Cancer Survivor Study. J Natl Cancer Inst 101(13): 946-958.

Armstrong GT, Liu W, Leisenring W, Yasui Y, Hammond S, Bhatia S, Neglia JP, Stovall M, Srivastava D, Robison LL (2011) Occurrence of multiple subsequent neoplasms in long-term survivors of childhood cancer: a report from the childhood cancer survivor study. J Clin Oncol 29(22): 3056-3064.

Atkinson SA, Halton JM, Bradley C, Wu B, Barr RD (1998) Bone and mineral abnormalities in childhood acute lymphoblastic leukemia: influence of disease, drugs and nutrition. Int J Cancer Suppl 11: 35-39.

Bolling T, Konemann S, Ernst I, Willich N (2008) Late effects of thoracic irradiation in children. Strahlenther Onkol 184(6): 289-295.

Boman KK, Hoven E, Anclair M, Lannering B, Gustafsson G (2009) Health and persistent functional late effects in adult survivors of childhood CNS tumours: a population-based cohort study. Eur J Cancer 45(14): 2552-2561.

Bowers DC, McNeil DE, Liu Y, Yasui Y, Stovall M, Gurney JG, Hudson MM, Donaldson SS, Packer RJ, Mitby PA, Kasper CE, Robison LL, Oeffinger KC (2005) Stroke as a late treatment effect of Hodgkin's disease: a report from the Childhood Cancer Survivor Study. J Clin Oncol 23(27): 6508-6515.

Breslow NE, Lange JM, Friedman DL, Green DM, Hawkins MM, Murphy MF, Neglia JP, Olsen JH, Peterson SM, Stiller CA, Robison LL (2010) Secondary malignant neoplasms after Wilms tumor: an international collaborative study. Int J Cancer 127(3): 657-666.

Cancer in Norway (2011) Cancer Incidence, Mortality, Survival and Prevalence in Norway. Kreftregisteret: Oslo, Norway, Available at: http:// www.kreftregisteret.no/no/Generelt/Nyheter/Cancer-in-Norway-2010/.

Cardous-Ubbink MC, Heinen RC, Bakker PJ, van den Berg H, Oldenburger F, Caron HN, Voute PA, van Leeuwen FE (2007) Risk of second malignancies in long-term survivors of childhood cancer. Eur J Cancer 43(2): 351-362.

Diller L, Chow EJ, Gurney JG, Hudson MM, Kadin-Lottick NS, Kawashima TI, Leisenring WM, Meacham LR, Mertens AC, Mulrooney DA, Oeffinger KC, Packer RJ, Robison LL, Sklar CA (2009) Chronic disease in the Childhood Cancer Survivor Study cohort: a review of published findings. J Clin Oncol 27(14): 2339-2355.

Doi K, Mieno MN, Shimada Y, Yoshinaga S (2009) Risk of second malignant neoplasms among childhood cancer survivors treated with radiotherapy: meta-analysis of nine epidemiological studies. Paediatr Perinat Epidemiol 23(4): 370-379.

Geenen MM, Cardous-Ubbink MC, Kremer LC, van den Bos C, van der Pal HJ, Heinen RC, Jaspers MW, Koning CC, Oldenburger F, Langeveld NE, Hart AA, Bakker PJ, Caron HN, van Leeuwen FE (2007) Medical assessment of adverse health outcomes in long-term survivors of childhood cancer. JAMA 297(24): 2705-2715.

Ghaderi S, Lie RT, Moster D, Ruud E, Syse A, Wesenberg F, Bjorge T (2012) Cancer in childhood, adolescence, and young adults: a population-based study of changes in risk of cancer death during four decades in Norway. Cancer Causes Control 23(8): 1297-1305.

Gustafsson G, Schmiegelow K, Forestier E, Clausen N, Glomstein A, Jonmundsson G, Mellander L, Makipernaa A, Nygaard R, Saarinen-
Pihkala UM (2000) Improving outcome through two decades in childhood ALL in the Nordic countries: the impact of high-dose methotrexate in the reduction of CNS irradiation. Nordic Society of Pediatric Haematology and Oncology (NOPHO). Leukemia 14(12): 2267-2275.

Haddy TB, Mosher RB, Reaman GH (2001) Osteoporosis in survivors of acute lymphoblastic leukemia. Oncologist 6(3): 278-285.

Hammer H (2002) The central population registry in medical research. Tidsskr Nor Laegeforen 122(26): 2550.

Hawkins MM, Lancashire ER, Winter DL, Frobisher C, Reulen RC, Taylor AJ, Stevens MC, Jenney M (2008) The British Childhood Cancer Survivor Study: objectives, methods, population structure, response rates and initial descriptive information. Pediatr Blood Cancer 50(5): 1018-1025.

Hjern A, Lindblad F, Boman KK (2007) Disability in adult survivors of childhood cancer: a Swedish national cohort study. J Clin Oncol 25(33): 5262-5266.

Johannesen TB, Langmark F, Wesenberg F, Lote K (2007) Prevalence of Norwegian patients diagnosed with childhood cancer, their working ability and need of health insurance benefits. Acta Oncol 46(1): 60-66.

Klosky JL, Howell CR, Li Z, Foster RH, Mertens AC, Robison LL, Ness KK (2012) Risky health behavior among adolescents in the childhood cancer survivor study cohort. J Pediatr Psychol 37(6): 634-646.

Kuehni CE, Rueegg CS, Michel G, Rebholz CE, Strippoli MP, Niggli FK, Egger M, von der Weid NX (2012) Cohort Profile: The Swiss Childhood Cancer Survivor Study. Int J Epidemiol 41(6): 1553-1564.

Larsen IK, Smastuen M, Johannesen TB, Langmark F, Parkin DM, Bray F, Moller B (2009) Data quality at the Cancer Registry of Norway: an overview of comparability, completeness, validity and timeliness. Eur J Cancer 45(7): 1218-1231.

Ministry of Labour (2011) The Norwegian Social Insurance Scheme. Ministry of Labour, Available at: http://www.regjeringen.no/en/dep/ad/doc/ veiledninger_brosjyrer/2011/the-norwegian-social-insurance-scheme-20. html?id=636557.

Mulrooney DA, Dover DC, Li S, Yasui Y, Ness KK, Mertens AC, Neglia JP, Sklar CA, Robison LL, Davies SM (2008) Twenty years of follow-up among survivors of childhood and young adult acute myeloid leukemia: a report from the Childhood Cancer Survivor Study. Cancer 112(9): 2071-2079.

Ness KK, Morris EB, Nolan VG, Howell CR, Gilchrist LS, Stovall M, Cox CL, Klosky JL, Gajjar A, Neglia JP (2010) Physical performance limitations among adult survivors of childhood brain tumors. Cancer 116(12): 3034-3044.

NIS (2010) Membership of the National Insurance Scheme. The Norwegian Labour and Welfare Administration. NIS, Available at: http://www.nav.no/ English/Membership+in+The+National+Insurance+Scheme.

Oeffinger KC, Mertens AC, Sklar CA, Kawashima T, Hudson MM, Meadows AT, Friedman DL, Marina N, Hobbie W, Kadan-Lottick NS, Schwartz CL, Leisenring W, Robison LL (2006) Chronic health conditions in adult survivors of childhood cancer. N Engl J Med 355(15): 1572-1582.

Patterson BC, Wasilewski-Masker K, Ryerson AB, Mertens A, Meacham L (2012) Endocrine health problems detected in 519 patients evaluated in a pediatric cancer survivor program. J Clin Endocrinol Metab 97(3): 810-818.

Robison LL, Mertens AC, Boice JD, Breslow NE, Donaldson SS, Green DM, Li FP, Meadows AT, Mulvihill JJ, Neglia JP, Nesbit ME, Packer RJ, Potter JD, Sklar CA, Smith MA, Stovall M, Strong LC, Yasui Y, Zeltzer LK (2002) Study design and cohort characteristics of the Childhood Cancer Survivor Study: a multi-institutional collaborative project. Med Pediatr Oncol 38(4): 229-239.

SEER (2011) Surveillance Epidemiology and End Results. National Cancer Institute, Available at: http://seer.cancer.gov/.

Shaw AK, Morrison HI, Speechley KN, Maunsell E, Barrera M, Schanzer D, Pogany L, Desmeules M (2004) The late effects study: design and subject representativeness of a Canadian, multi-centre study of late effects of childhood cancer. Chronic Dis Can 25(3-4): 119-126.

Sieswerda E, Postma A, van Dalen EC, van der Pal HJ, Tissing WJ, Rammeloo LA, Kok WE, van Leeuwen FE, Caron HN, Kremer LC (2012) The Dutch Childhood Oncology Group guideline for follow-up of asymptomatic cardiac dysfunction in childhood cancer survivors. Ann Oncol 23(8): 2191-2198.

Stensheim H, Cvancarova M, Moller B, Fossa SD (2011) Pregnancy after adolescent and adult cancer: a population-based matched cohort study. Int J Cancer 129(5): 1225-1236. 
The Norwegian Labour and Welfare Administration (2012) NAV, Available at: http://www.nav.no/English.

Thorsen L, Gjerset GM, Loge JH, Kiserud CE, Skovlund E, Flotten T, Fossa SD (2011) Cancer patients' needs for rehabilitation services. Acta Oncol 50(2): $212-222$.

Turner CD, Rey-Casserly C, Liptak CC, Chordas C (2009) Late effects of therapy for pediatric brain tumor survivors. J Child Neurol 24(11): 1455-1463.

Whelan KF, Stratton K, Kawashima T, Waterbor JW, Castleberry RP, Stovall M, Sklar CA, Packer RJ, Mitby P, Aitken CL, Blatt J, Robison LL, Mertens AC (2010) Ocular late effects in childhood and adolescent cancer survivors: a report from the childhood cancer survivor study. Pediatr Blood Cancer 54(1): 103-109.
WHO (2011) ICD Systems. World Health Organization: Geneva, Switzerland, Available at: http://www.who.int/classifications/icd/.

Woodward E, Jessop M, Glaser A, Stark D (2011) Late effects in survivors of teenage and young adult cancer: does age matter? Ann Oncol 22(12): 2561-2568.

This work is published under the standard license to publish agreement. After 12 months the work will become freely available and the license terms will switch to a Creative Commons AttributionNonCommercial-Share Alike 3.0 Unported License. 